\title{
Magnetic observations at Geophysical Observatory Paratunka IKIR FEB RAS: tasks, possibilities and future prospects
}

\author{
Sergey Y. Khomutov * \\ ${ }^{1}$ Institute of Cosmophysical Research and Radio Wave Propagation FEB RAS, 684034, \\ Kamchatskiy Kray, Paratunka, Mirnaya st., 7, Russia
}

\begin{abstract}
Continuous magnetic measurements at Geophysical Observatory "Paratunka" (PET) of IKIR FEB RAS are performed since 1967. In the new millennium analogue magnetometers were modernized to digital, the technologies of absolute observations were changed, the data processing was completely transferred to computers, and the status of INTERMAGNET observatory was obtained. Currently, the observatory uses the following magnetometers: (a) for absolute observations - DIflux LEMI-203 (theodolite 3T2KP) and Mag-01 (theodolite Wild-T1), Overhauser magnetometers POS-1 and GSM19W; (b) for variation measurements - fluxgate magnetometers FGE-DTU, FRG-601 and MAGDAS (installed under international agreements of IKIR), vector magnetometers dIdD GSM-19FD and POS-4 with Overhauser sensors and coil systems, scalar magnetometer GSM-90 and induction magnetometer STELAB. During Spring-Autumn season dIdD also is installed at remote station "Karymshina" at distance of $15 \mathrm{~km}$ from $\mathrm{Ob}$ servatory. There is monitoring system for monitoring of conditions in which magnetic observations are performed, including the semi-professional weather stations Davis Vantage Pro2 and WS2000 and a network of digital temperature sensors DS19B20 located at various points in magnetic pavilions and outdoor. All measurements are synchronized with the UTC. The results of observations are collected by the IKIR data server from the recorders and loggers, including in real-time. Specialized software was developed (based on MATLAB and Octave packages), which allows automatic and semi-automatic processing of data, the comparison of the results from different magnetometers and presenting final data in formats, defined by international standards, including INTERMAGNET. Significant efforts of observatory staff are direct to archive (raw) magnetic data, a significant part of which has not been entirely processed, is not presented in international data centers and is still not available to the scientific community. Digital images of analog magnetograms have been obtained, the digitization of which allowed to fill the gaps in the hourly data available in the WDC for 1991, 1996-1997. The state of the set of the instruments and databases shows that the observatory "Paratunka" can solve most of the problems that arise in the geomagnetic field researches, including the provision of data for the development of regional and global field models, ground support of magnetometers located on satellites, support of the surface (sea) and aeromagnetic surveys and
\end{abstract}

^e-mail: Khomutov@ikir.ru

This work was supported by the Grants of RSF No.14-11-00194 and RFBR No.16-55-45007 
drilling, providing the data for researches of processes in the lithosphere, magnetosphere and ionosphere over a wide frequency range, and also for a number of applied problems.

\section{Introduction}

Magnetic observatories (MOs) perform long-term standard observations that provide information about the magnetic field, and are an important element of the experimental base of scientific and applied research. The distribution of MOs over the Earth and over time is very heterogeneous: some MOs perform observations during hundreds of years, some MOs have been created in recent years; in some regions the density of the MO network is high, but also there is no observatories over large area. Only a few active MOs existed on the territory of the USSR until about the middle of the last century. However, the results of the International Geophysical Year showed that this network is unsatisfactory. In accordance with the Goverment decision the new network of Joint magnetoionospheric stations (KMIS) was designed and in the late 60s of the last century it was deployed. KMIS in Kamchatka later became the Geophysical Observatory (GFO) Paratunka, the international code PET (IAGA). In the last century magnetic measurements on the GFO were carried out using Bobrov's quartz variometers with recording on a photographic tape in accordance with IAGA standards. The result of these regular measurements is the database of hourly data on the total field vector (www.wdc.bgs.ac.uk/catalog/master.html, WDC for geomagnetism) and also the database of digital images of analog magnetograms (www.wdcb.ru/stp/magnetogr_list.en.html, WDC for SolarTerrestrial Physics).

The modernization of GFO Paratunka began at the end of the 1990s due to international cooperation. The digital magnetometers for vector and scalar measurements and new instruments for absolute observations were installed, the infrastructure of the observatory developed, new methods for digital processing of magnetic data were introduced. The observatory gradually achieved the modern standards of measurements and in 2013 got the status of the observatory of the INTERMAGNET network (www.intermagnet.org).

The goal of this report is to show the current state of magnetic measurements on the GFO Paratunka, including hardware, software and methodological support, and to note the some results and the possibility of their application in various scientific and applied tasks. The actuality of this report is due to there is no detailed description of observatory over all its history in publications.

\section{Location, measurement conditions and infrastructure}

The Institute of Cosmophysical Research and Radio Wave Propagation (IKIR) FEB RAS and Observatory Paratunka as department of IKIR are located about $25 \mathrm{~km}$ to south-west from PetropavlovskKamchatsky, to west from Avacha Bay, on the northern outskirts of the village Paratunka. In a significant area around observatory (within a radius of $10 \mathrm{~km}$ ) there are no industrial facilities and other sources of industrial disturbance. The main consumers of electricity, i.e. potential sources of noise, are large number of sanatoriums and recreation centers in the vicinity of the village Paratunka.

Figure 1 shows the main infrastructure objects of institute and observatory and some measurement systems. The building of ionospheric station 2, technical building 11, garage with workshops 10 and magnetic huts 3, 4, 5 were built in 1965-1967 as KMIS objects. At the same time, there were built two three-storey apartment houses 12 for KMIS staff. The main building 1 of the institute was built later, in the late 80's. On the meadow 7 the sensors of the STELAB induction magnetometer are installed (buried in the ground), the area around the sensors is cleared of trees to reduce wind effects. On the 
meadow 8 there is an electric field meter Pole-2 for measuring the vertical gradient of the potential of the atmospheric electric field. The meadow is cleared from the trees to avoid distortion of the field distribution around the sensor Pole-2. There is a special remote mark 9 (target) on the western wall of residential house. The azimuth of target (209 $\left.48^{\prime} 56^{\prime \prime}\right)$ is determined every year by the astronomical observations of the Sun. This mark is necessary to obtain a magnetic declination D using the results of the absolute observations in pavilion 4 . The visibility of the target is provided by a special glade 300 $\mathrm{m}$ long. Along the direction to main target at a distance of about $200 \mathrm{~m}$ from the absolute pavilion, an additional mark was installed. This additional target is located at guarded area of IKIR and used during absolute observations in bad weather conditions. There are several old abandoned buildings and two wells providing residential houses and the institute with water. Main well is located near $50 \mathrm{~m}$ to the northeast of the institute building, cased with a steel pipe to a depth of about $100 \mathrm{~m}$, with a submersible pump. Figure 2 shows a panoramic photograph of the magnetic pavilions (variation, absolute and for POS-4).

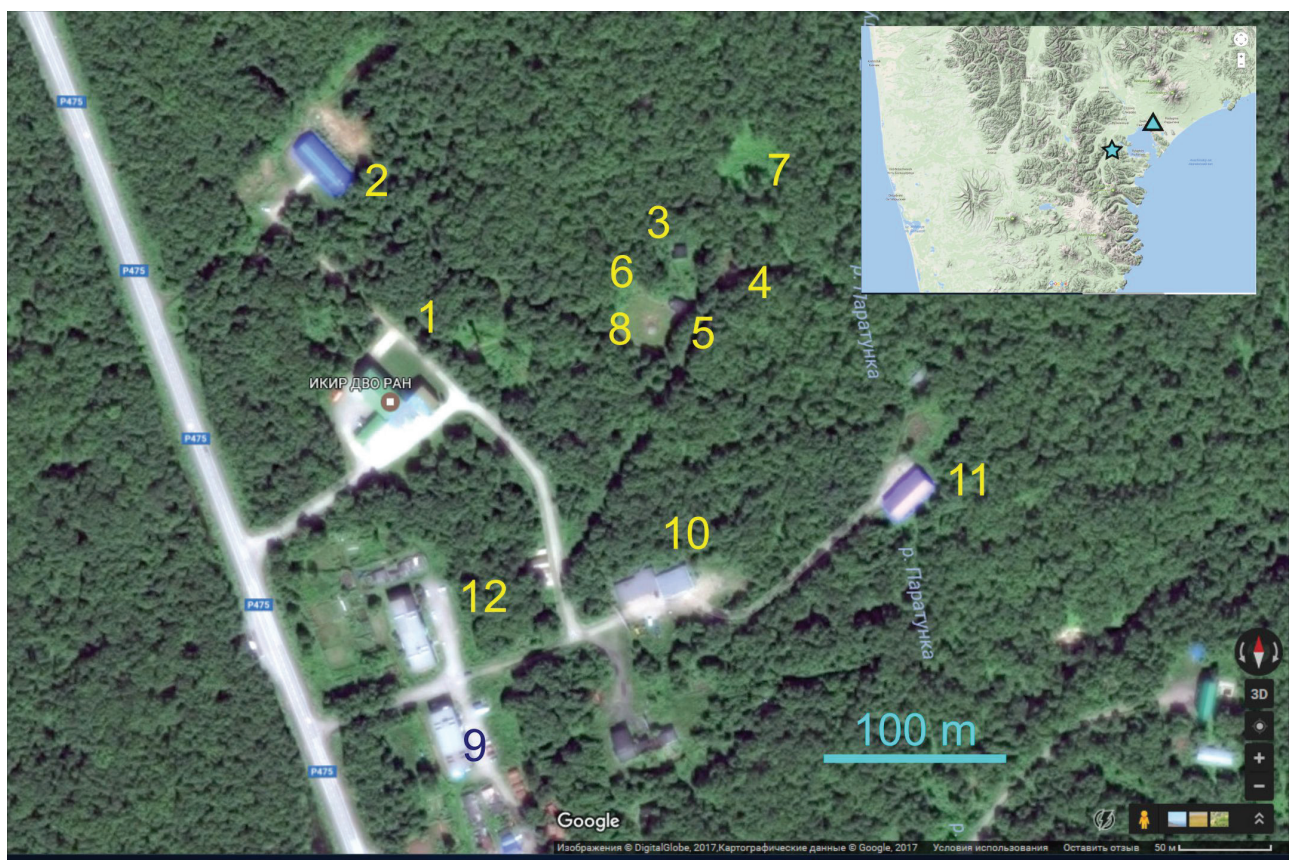

Figure 1. The location of the main buildings and objects near Observatory (from www.google.ru/maps/). 1 main building of institute; 2 - building of ionospheric station (working and office rooms, lidar, ionosonde Parus with vertical dipole transmitting antenna oriented in SE-NW direction); 3 - pavilion for variation measurements (magnetometers FGE, GSM-90, MAGDAS, FRG-601); 4 - pavilion for absolute observations (magnetometers LEMI-203, Mag-01H, POS-1); 5 - technical pavilion; 6 - pavilion for magnetometer dIdD GSM-19FD; 7 sensors of induction magnetometer STELAB; 8 - area with electric field meter Pole-2; 9 - azimuthal target at wall of house, the its visibility from absolute pavilion is provided by glade; 10 - garage and workshops; 11 service building; 12 - two three-store buildings. The POS-4 pavilion is placed between pavilions 3 and 4 . At the left of photo there is federal road between Paratunka and Petropavlovsk-Kamchatsky. The framing shows the map of central part of Kamchatka with Petropavlovsk-Kamchatsky ( $\mathbf{\Lambda})$ and Paratunka ( $\star$ ). 


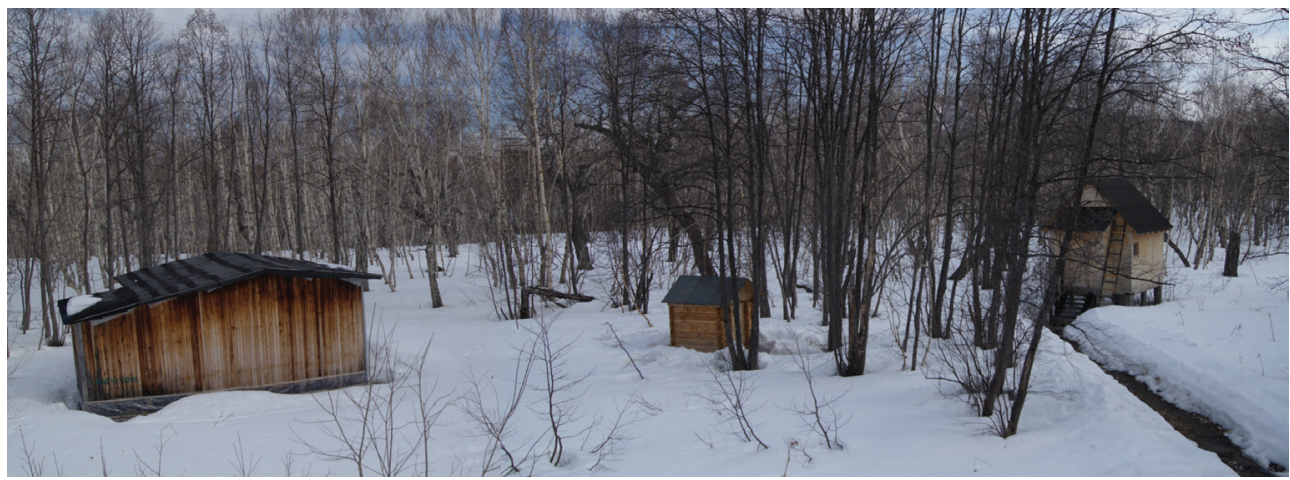

Figure 2. The main pavilions of Observatory Paratunka: variation (left), POS-4 (center) and absolute (right). Photo was made from roof of technical pavilion at April, 2016.

\section{The pavilion for absolute magnetic observations (absolute pavilion)}

The absolute pavilion is the most important at the observatory because the absolute observations are supplied the reliability and stability of magnetic field long-time series. Especially high requirements for magnetic cleanliness are met to this pavilion and to the nearby area. The old absolute pavilion was built in 1967. It had the size of 3x3 m and was constructed of wooden beam and there were four larch pillars for magnetometer installation. For forty years there was a destruction of both the walls and the buried part of the pillars. This made problems during observations and reduced the accuracy of the results.

In 2009 the new absolute pavilion with wall from a wooden beam was installed at the place of old one, the size is $3 \times 3 \mathrm{~m}$. Two important points were taken into account. (1) There is a high magnetization of the underlying rocks, which led to significant vertical gradient of field. (2) The snow level during winter season reaches 1-2 m above the absolute hut window used for observation of remote target 9 (see Fig. 1) was reached. Bulldozer is need to clear the glade from the snow, but this causes the significant disturbances of magnetic field. Therefore the new absolute pavilion was raised on piles, height of working floor is about $1.5 \mathrm{~m}$. The piles are an asbestos-cement pipes filled with nonmagnetic crushed stone. Two pillars were installed in the pavilion. Bottom part of pillars (below the floor level) are also made of asbestos-cement pipes, top part of pillars from about $0.5 \mathrm{~m}$ below the floor and inside the pavilion are made from glass blocks (see Fig. 3e). The working height of the pillar is about $1.5 \mathrm{~m}$, cross section is $40 \mathrm{x} 40 \mathrm{~cm}$, a thick glass plate is glued on the upper surface. The long-term stability of the main pillar is quite high: the astronomical measurements of the remote target azimuth over last three years have shown that the azimuth changes do not exceed 10", that is close to the astronomical observation error. The possible pillar movements across the direction to the target are no more than 1-2 cm. The pavilion has large area of the side due to a high pointed roof. This causes the oscillations of pavilion and pillar during strong wind, but dos not effect the results of absolute observations. The position of pillars in pavilion provide the visibility of remote target from both pillars.

For heating of the pavilion in the cold season, a heater with a Nichrome spiral and a mechanical thermoregulator are used, during warm season the heating is turned off. The temperature in the pavilion is controlled by the digital temperature sensor DS18B20 [1], the results of measurements are recorded to computer every 10 seconds. Also here are the DIflux magnetometers LEMI-203 (Fig. 3e) 


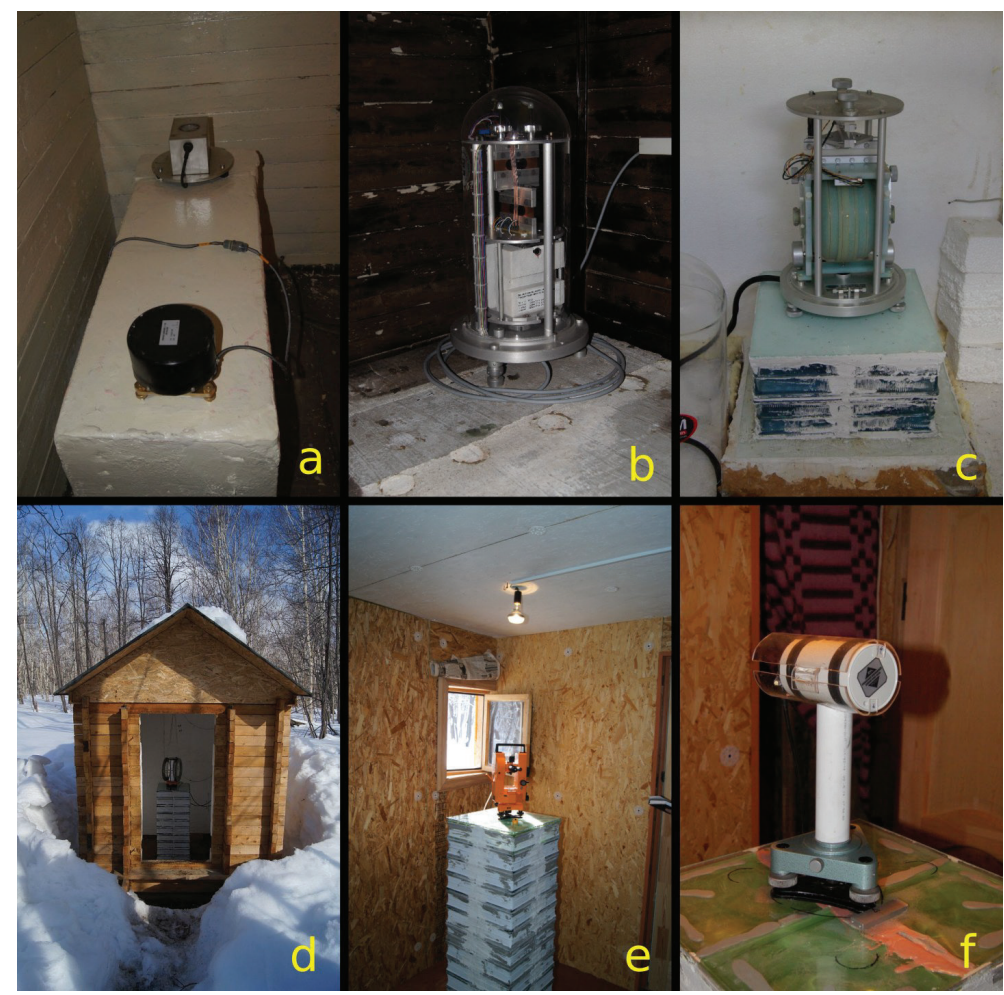

Figure 3. Magnetometers of the Observatory Paratunka: (a) the sensors of the fluxgate magnetometers Magdas (in front) and FRG-601 (at the back) in the variation pavilion; (b) - the suspended sensor block of the fluxgate magnetometer FGE in the variation pavilion; (c) - sensor of magnetometer dIdD GSM-19FD on a low pillar in a special pavilion; (d) - pavilion of the magnetometer POS-4 with a sensor on the pillar; (e) - DIflux LEMI-203 on the main pillar in the absolute pavilion with the window to observe the remote target (at the back); (f) - sensor of magnetometer POS-1 on the main pillar in the absolute pavilion.

and Mag-01H and the Overhauser scalar magnetometer POS-1 (Fig. 3f) for absolute determinations $(\mathrm{D}, \mathrm{I})$ and F, respectively.

The change of the pavilion led to the jumps in the long-term series of magnetic data. For example, the declination has changed by 1', the horizontal component by $2 \mathrm{nT}$, the vertical component by $20 \mathrm{nT}$. The possible reason is the little shift of the absolute observation point under conditions of sufficiently high spatial gradients of field.

\section{The pavilion for variation magnetic measurements (variation pavilion)}

The variation pavilion was built in 1967 according to a typical KMIS project: a size is about $6 \times 6 \mathrm{~m}$ with a lobby, the material of the main walls is a wooden balk trimmed from the outside with boards. The gable roof has as light slope. Inside the pavilion there is a chamber of planks, which provides thermal insulation of the internal space with pillars. The four pillars are made from the lime-cement mixture, three of which (main) are oriented in the direction of "north-south" and one with the orientation "east-west". The eastern main pillar is place for fluxgate sensors of the component magnetometer FGE-DMI (Fig. 3b), the western main pillar is place for the fluxgate sensors of MAGDAS and FRG- 
601 magnetometers (Fig. 3a). Scalar Overhauser magnetometer GSM-90 is installed on the roof of the inner chamber. Recorder Magdalog is placed at the wall inside the camera, GSM-90 console and the electronics of the FGE and GSM-90 magnetometers are installed at outside wall of pavilion.

Heating of the variation pavilion is carried out by a heater with a Nichrome spiral and an additional low-power heater, which is switched on in winter as a background heater. Both heaters are installed between the outer wall and the inner chamber, the temperature stability is maintained by a mechanical temperature regulator, also located between outer and inner walls. There are four digital temperature sensors DS18B20 in the pavilion: one between outer and inner walls and three in the inner chamber (near the floor, at the level of pillars and near the ceiling). The data are recorded every 5 seconds. In order to provide the regulation of temperature with limited heaters capacity, the level of the temperature of the switching of the heater raises up to $+(18-20)^{\circ} \mathrm{C}$ during the summer and decreases up to $+(12-13)^{\circ} \mathrm{C}$ during the winter. Because the limited heating of the pavilion the high stability of temperature is also restricted. Therefore, the absolute magnetic observations are made very often, generally twice per day. The baseline values obtained make it possible more effectively control the temperature effects in variometer records. For example, Figure 4 (left panel) shows the minute values of the temperature of recorder Magdalog installed in inner chamber for 2013-2016. It is seen that temperature conditions in pavilion was noticeably stabilized as the results of the improvement of the thermal insulation of the outer wall of the pavilion in November 2014. The points of the switching of the temperature control device to summer (June-July) and winter (October-November) modes are also visible.
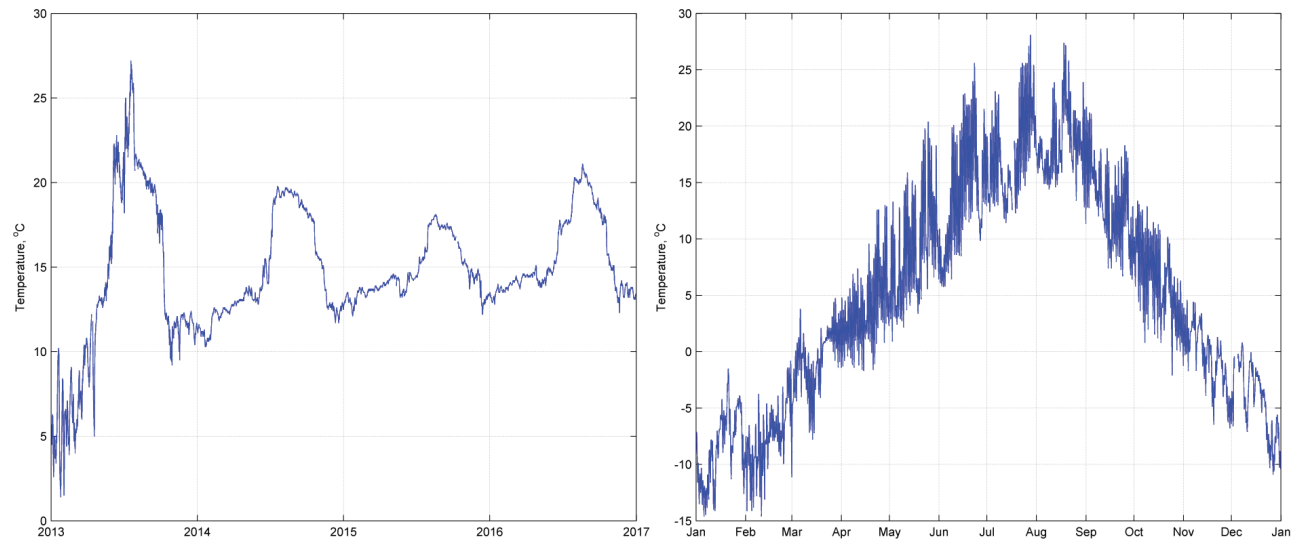

Figure 4. The temperature in inner chamber of the variation pavilion inside the recorder Magdalog for 2013-2016 (left panel) and in pavilion of dIdD for 2016 (right panel).

\section{Pavilion for recording and auxiliary equipment (technical pavilion)}

The technical pavilion is built simultaneously with other magnetic pavilions and is a wooden plastered building about $6 \times 6 \mathrm{~m}$ in size with a gable roof. It contains recording computers, control electronics and data acquisition systems for some magnetometers, power supply systems, including uninterruptible power supplies, communication devices, GPS systems and antennas for timing synchronization, etc. There are also spares and temporary workplace for service staff. In winter, a small heater is used to support the temperature conditions. The digital sensor DS18B20 is installed to control the temperature. All the recording computers in the technical pavilion are connected to the local network and 
connected to the main building of the institute by means of a fiber-optic line. This ensures the on-line monitoring of the state of measuring systems and online access to data from personal computers of staff of Observatory.

\section{The pavilion for the magnetometer dIdD GSM-19FD}

The pavilion for the magnetometer dIdD GSM-19FD was built in 2011 at some distance from other magnetic pavilions, because dIdD creates significant disturbations of the magnetic field around itself. The experiments with installation of dIdD in the variation pavilion at Observatory Paratunka and also at other magnetic observatories of IKIR shown that effect can reach up to $10 \mathrm{nT}$ at distances of the 1-2 $\mathrm{m}$ and tenths of $\mathrm{nT}$ at distance of up to $5 \mathrm{~m}$ ([2], [3]).

The pavilion is a low building about $1 \times 2 \mathrm{~m}$ in size from a timbers with expanded polystyrene plates $10 \mathrm{~cm}$ thick on the inner side of the walls and the roof. The roof is gable and steep. The entrance door is missing — the access inside provides the attic hole, which is closed by a lid fixed with brass bolts. The floor is also absent and the foam polystyrene boards are used for thermal insulation. The pillar is made of glass blocks, has a cross section of $40 \times 40 \mathrm{~cm}$ and is buried at $0.5 \mathrm{~m}$. The height of pillar above the ground is about $0.2 \mathrm{~m}$. The dIdD sensor is mounted on the pillar (Fig. 3c), the console is also inside the pavilion. The magnetometer is controlled by standard shielded twisted-pair cable via RS232 protocol. Power $220 \mathrm{~V}$ for the console is supplied from the technical pavilion by cable. The digital temperature sensor DS18B20 is installed inside the pavilion. Active heating is not used, therefore the indoor temperature is close to the outdoor temperature, but more smoothed due to thermal insulation (see Fig. 4, right panel). Because of the small height the pavilion is almost entirely covered with snow during winter and spring, this improves the stability of thermal conditions inside.

\section{The pavilion for the magnetometer POS-4}

The pavilion for the magnetometer POS-4 was built in 2015 at a distance from other magnetic pavilions (place is selected between pavilions 3 and 4, see Fig. 1 and 2). The reason is the same as for the pavilion of the $\mathrm{dIdD}$, because the vector magnetometer POS- 4 is close to the $\mathrm{dIdD}$ by technology: a scalar Overhauser sensor is placed inside the ring system. Therefore, it causes field disturbations in the vicinity during operation (the magnitude of the effect was not estimated). The pavilion about $2.0 \times 2.5 \mathrm{~m}$ in size with a wall height of about $1.7 \mathrm{~m}$ is built of timbers without a foundation. The gable roof made of chipboard has a height in the center of about $0.5 \mathrm{~m}$, that makes it possible to work with a magnetometer quite comfortably. On the inside of the walls and roof fixed panels of polystyrene $10 \mathrm{~cm}$ thick. The door is a plate insulated with expanded polystyrene and in the closed position is fixed by four brass bolts. The floor is absent, but insulating panels are laid on the ground (Fig. $3 \mathrm{~d}$ ).

The pillar is composite, the underground part is cast from a sand-cement mixture to a depth of about $1 \mathrm{~m}$, the overgound part with height of $1 \mathrm{~m}$ and a section of $40 \times 36 \mathrm{~cm}$ is made of glass blocks with a thick glass plate on top. Continuous measurements with POS-4 during autumn 2015 - spring 2016 showed that due to freezing and defrosting of the ground the pillar tilts, creating significant trends of non-magnetic origin in the results [4]. Therefore, in the autumn of 2016 the lower part of the pillar was enlarged up to $90 \times 80 \mathrm{~cm}$ in cross-section, its lateral planes were thermally insulated with expanded polystyrene and isover, and between the pillar and the ground an air gap of 10-20 cm was left insulated from the top. POS-4 measurements during the winter season of 2016-2017 shows, that this update proved to be quite effective against freezing and defrosting.

Communication and power supply of the magnetometer is provided by cable from the instrument kit, protocol is RS232. In contrast to the pavilion of dIdD, the pavilion of POS-4 does not have $220 \mathrm{~V}$ power. Heating is not used, the temperature is controlled by three sensors DS18B20: on the cover of the magnetometer electronics to control of possible overheating in summer and on the north wall at 
a height of about $1 \mathrm{~m}$. The third sensor after updating of pillar was lowered into the air gap between pillar and ground to a depth of about $0.6 \mathrm{~m}$. Because of the considerable dampness in the gap and the risk of flooding with groundwater during the spring 2017 it was reinstalled to the north wall of the pavilion at floor level. It should again be noted that due to the small size of the pavilion, in winter it is covered with snow almost to the roof, this significantly stabilizes the temperature inside.

\section{Magnetometers and other measuring systems}

The Geophysical Observatory Paratunka is quite typical division of the KMIS network and has passed the standard way of its development in the USSR and then in the Russian Federation. The same applies to the evolution of equipment used in magnetic monitoring: from variometers based on Bobrov's quartz sensors with analog recording and QHM quartz magnetometers for absolute observations to digital variation systems and absolute instruments based on nonmagnetic theodolites and Overhauser scalar sensors.

In the 1990s, the first component fluxgate magnetometers such as DCR, MAGDAS and FRG-601 were installed at observatory under of international agreements of IKIR with scientific organizations of Japan. At the same time, the Russian system on the basis of the digital magnetic variation station "Quartz-6" (IZMIRAN) with Bobrov's quartz sensors was developed. MMP-203 proton magnetometers and quantum M-61 magnetometers were used to measure the total field intensity. Significant progress was made at the beginning of the 21st century: the development of the observatory was focused on achieving the standards of the INTERMAGNET network [5]. Thanks to such trends the GFZ German Research Centre for Geosciences (Potsdam, Germany) in 2009 provided a full set of equipment for the variation magnetic measurements in accordance with new standards (fluxgate magnetometer FGE-DMI, scalar magnetometer GSM-90F1, recorder Magdalog) and modern absolute DIflux magnetometer LEMI-203 was received under INTAS project CRENEGON in 2004 [6]. Vector magnetometers dIdD GSM-9FD and scalar Overhauser magnetometer GSM-19W were purchased. The update of the measuring devices together with organizational arrangements and the development of software led to success - in 2013 the Paratunka was certified as an observatory of the INTERMAGNET. However, the modernization of experimental base is continued, as one of the ways to increase the reliability and quality of magnetic measurements, and as tendency of transition to domestic developments. So, Overhauser magnetometers were purchased under support of the Russian Science Foundation grant (a scalar POS-1 and a vector POS-4), the software package that provides for the joint processing of a significantly increased amount of data was developed with support of Russian Foundation for Basic Research (RFBR).

At present, the system for monitoring the magnetic field at the Observatory Paratunka includes a set of magnetometers operating on different principles and in different modes, a software system and a developed system of auxiliary equipment. The general diagram of these devices in pavilions, recording and communication systems and other devices is shown in Fig. 5. The list of magnetometers used in 2017 on the Observatory Paratunka and their main specifications are presented in Table 1 and 2. The diagram in Fig. 5 is rather simplified, for example, there are not shown magnetometer power supplies (main and emergency ones), communication lines and recorded computers of the digital temperature sensors, DIflux magnetometers in the absolute pavilion, etc. The arrangement of instruments is shown schematically, e.g., without their height separation or real spatial scales. Nevertheless, Fig. 5 makes it possible to assess the structural complexity of the system as a whole, which, in general, can be a source of noise and interference and greatly complicates the maintenance of the equipment, its tuning or repair.

We note the following features of the measuring system: 


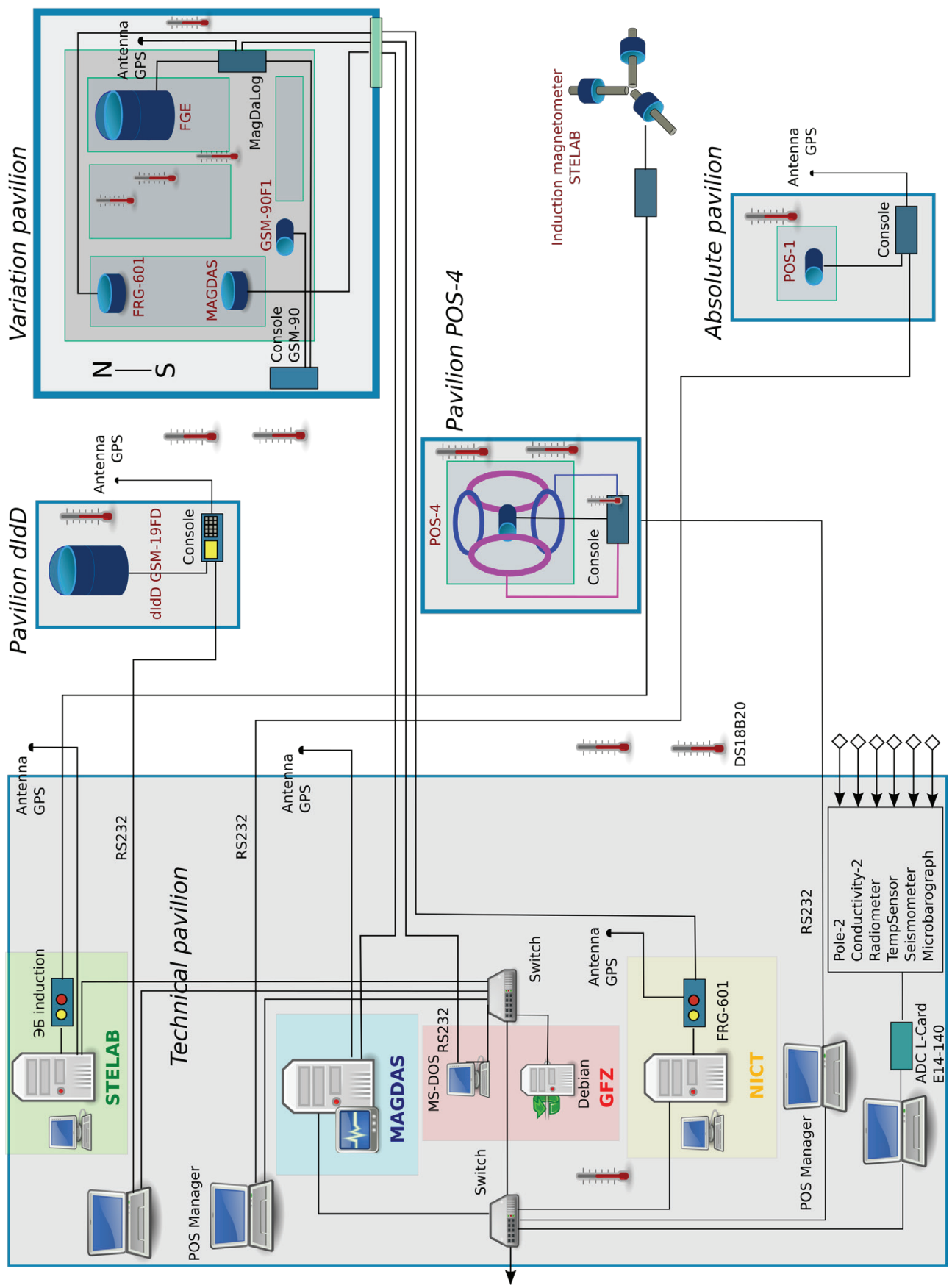

Figure 5. The diagram of the location of main devices of system of the magnetic field monitoring. 
Table 1. Variation magnetometers at Observatory Paratunka, 2017

\begin{tabular}{|c|c|c|c|}
\hline Name & Type & Specifications & Manufacturer \\
\hline FGE & fluxgate & $\begin{array}{l}\text { - variations } \mathrm{dH}, \mathrm{dD}, \mathrm{dZ} \\
\text { - resolution } 0.1 \mathrm{nT} \\
\text { - dynamic range } \pm 10000 \mathrm{nT} \text { (regulated) } \\
\text { - sampling } 2 \mathrm{~Hz} \\
\text { - temperature dependence } 0.25 \mathrm{nT} /{ }^{\circ} \mathrm{C} \\
\text { - longtime trends less } 3 \mathrm{nT} / \text { year } \\
\text { - suspended system } \pm 0.5^{\circ} \mathrm{C} \\
\text { - recorder Magdalog }(\text { Germany) } \\
\text { - GPS-synchronization }\end{array}$ & $\begin{array}{l}\text { DMI, Denmark } \\
\text { GFZ, Germany }\end{array}$ \\
\hline MAGDAS & fluxgate & $\begin{array}{l}\text { - variations } \mathrm{dH}, \mathrm{dD}, \mathrm{dZ} \\
\text { - resolution } 0.061 \mathrm{nT} / \mathrm{bin} \mathrm{ADC} \\
\text { - variation range } \pm 2000 \mathrm{nT} \\
\text { - sampling } 1 \mathrm{~Hz} \\
\text { - tilts NS and } \mathrm{EW} \text { - resolution } 0.2^{\prime \prime} \text { in range } \\
\pm 1^{\circ} \text {, sampling } 1 \mathrm{~min} \\
\text { - temperature of sensor - resolution } 0.01^{\circ} \mathrm{C} \\
\text { in range } \pm 60^{\circ} \mathrm{C} \text {, sampling } 1 \text { min } \\
\text { - GPS-synchronization }\end{array}$ & $\begin{array}{l}\text { ICSWSE, Kyushu } \\
\text { Univ., Japan [7] }\end{array}$ \\
\hline FRG-601 & fluxgate & $\begin{array}{l}\text { - variations } \mathrm{dH}, \mathrm{dD}, \mathrm{dZ} \text { - dynamic range } \\
\pm 65000 \mathrm{nT} \\
\text { - resolution } 0.5 \mathrm{nT} \\
\text { - sampling } 1 \mathrm{~Hz} \\
\text { - GPS-synchronization }\end{array}$ & NICT, Japan \\
\hline $\begin{array}{l}\text { dIdD } \\
\text { GSM- } \\
\text { 19FD }\end{array}$ & $\begin{array}{l}\text { Overhauser } \\
\text { scalar sensor } \\
\text { in coil system }\end{array}$ & $\begin{array}{l}\text { - variations dD, dI, total field intesity F } \\
\text { - sensitivity of } \mathrm{F} 0.18 \mathrm{nT} \text {, resolution } 0.1 \mathrm{nT} \\
\text { - uncertainty of dI less than } 1 ", \text { of } \mathrm{dD} \text { less } \\
\text { than } 4 " \\
\text { - dynamic range } 20000-120000 \mathrm{nT}(\mathrm{F}), \\
\pm 180^{\circ}(\mathrm{D}), \pm 90^{\circ}(\mathrm{I}) \\
\text { - sampling } 0.2-1.0 \mathrm{~Hz} \\
\text { - GPS-synchronization }\end{array}$ & $\begin{array}{l}\text { GEM Systems, } \\
\text { Canada [8] }\end{array}$ \\
\hline POS-4 & $\begin{array}{l}\text { Overhauser } \\
\text { scalar sensor } \\
\text { in coil system }\end{array}$ & $\begin{array}{l}\text { - total field components } \mathrm{F}, \mathrm{Z}, \mathrm{Y}(\mathrm{X}) \\
\text { - dynamic range } \mathrm{F} 20000-100000 \mathrm{nT} \text {, com- } \\
\text { ponents } \pm 20000 \mathrm{nT} \\
\text { - sensitivity F less than } 0.05 \mathrm{nT} \text {, compo- } \\
\text { nents less than } 0.3 \mathrm{nT} \\
\text { - absolute error F less than } 1 \mathrm{nT}, \mathrm{Z} \text { less than } \\
\text { 3-10 nT, horizontal component - no spec- } \\
\text { ify } \\
\text { - rate of readings } 1 \mathrm{sec} \text { and more }\end{array}$ & $\begin{array}{l}\text { Ural Federal Uni- } \\
\text { versity, Quantum } \\
\text { Magnetometry Labo- } \\
\text { ratory, Ekaterinburg, } \\
\text { Russia }\end{array}$ \\
\hline STELAB & induction & $\begin{array}{l}\text { - variations (derivatives) } \mathrm{dH}, \mathrm{dD}, \mathrm{dZ} \\
\text { - sensitivity } 0.45 \mathrm{~V} / \mathrm{nT} \text { at } 1.8 \mathrm{~Hz}, 0.02 \mathrm{~V} / \mathrm{nT} \\
\text { at } 0.1 \mathrm{~Hz} \\
\text { - sampling } 64 \mathrm{~Hz} \text {, turnover frequency } 1.8 \\
\mathrm{~Hz} \\
\text { - GPS-synchronization }\end{array}$ & $\begin{array}{l}\text { ISEE, Nagoya Univ., } \\
\text { Japan }\end{array}$ \\
\hline
\end{tabular}


Table 2. Scalar and absolute magnetometers at Observatory Paratunka, 2017

\begin{tabular}{|c|c|c|c|}
\hline Name & Type & Specifications & Manufacturer \\
\hline POS-1 & $\begin{array}{l}\text { Overhauser } \\
\text { scalar sensor }\end{array}$ & $\begin{array}{l}\text { - total field intensity } \mathrm{F} \\
\text { - absolute error less than } 1 \mathrm{nT} \\
\text { - uncertainty less then } 0.03 \mathrm{nT} \\
\text { - dynamic range } 20000-100000 \mathrm{nT} \\
\text { - rate of readings from } 1 \mathrm{sec} \text { and more } \\
\text { - GPS-synchronization }\end{array}$ & $\begin{array}{l}\text { Ural Federal Uni- } \\
\text { versity, Quantum } \\
\text { Magnetometry Labo- } \\
\text { ratory, Ekaterinburg, } \\
\text { Russia [9] }\end{array}$ \\
\hline $\begin{array}{l}\text { GSM- } \\
90 \mathrm{~F} 1\end{array}$ & $\begin{array}{l}\text { Overhauser } \\
\text { scalar sensor }\end{array}$ & $\begin{array}{l}\text { - total field intensity F } \\
\text { - resolution } 0.01 \mathrm{nT} \\
\text { - absolute error } 0.2 \mathrm{nT} \\
\text { - dynamic range } 20000-120000 \mathrm{nT} \\
\text { - rate of readings from } 1 \mathrm{sec} \text { and more } \\
\text { - Magdalog recorder (Germany) } \\
\text { - GPS-synchronization }\end{array}$ & $\begin{array}{l}\text { GEM Systems, } \\
\text { Canada [10] }\end{array}$ \\
\hline $\begin{array}{l}\text { GSM- } \\
19 \mathrm{~W}\end{array}$ & $\begin{array}{l}\text { Overhauser } \\
\text { scalar sensor }\end{array}$ & $\begin{array}{l}\text { - total field intensity F } \\
\text { - resolution } 0.01 \mathrm{nT} \\
\text { - absolute error } 0.1 \mathrm{nT} \\
\text { - dynamic range } 20000-120000 \mathrm{nT} \\
\text { - rate of readings from } 0.2 \mathrm{sec} \text { and more } \\
\text { - GPS-synchronization }\end{array}$ & $\begin{array}{l}\text { GEM Systems, } \\
\text { Canada [11] }\end{array}$ \\
\hline $\begin{array}{l}\text { LEMI- } \\
203\end{array}$ & $\begin{array}{l}\text { Fluxgate } \\
\text { sensor on } \\
\text { nonmagnetic } \\
\text { theodolite }\end{array}$ & $\begin{array}{l}\text { - declination D and inclination I } \\
\text { - range of fluxgate sensor } 2000-100000 \\
\text { nT } \\
\text { - resolution of sensor } 0.01 \mathrm{nT} \text { (for range } \\
2000 \mathrm{nT} \text { ) } \\
\text { - theodolite 3T2KP (UOMZ, Ekaterinburg) } \\
\text { - scaling division 1" } \\
\text { - accuracy - 5" }\end{array}$ & LC ISR, Ukraine \\
\hline Mag-01H & $\begin{array}{l}\text { Fluxgate } \\
\text { sensor on } \\
\text { nonmagnetic } \\
\text { theodolite }\end{array}$ & $\begin{array}{l}\text { - declination D and inclination I } \\
\text { - range of fluxgate sensor } \pm 200000 \mathrm{nT} \\
\text { - resolution of sensor } 0.1 \mathrm{nT} \\
\text { - theodolite Wild-T1 (WILD Heerbrugg, } \\
\text { Switzerland) } \\
\text { - scaling division 6" } \\
\text { - accuracy 3" }\end{array}$ & $\begin{array}{l}\text { Bartington Instru- } \\
\text { ments, GB [12] }\end{array}$ \\
\hline
\end{tabular}

1) all fluxgate variation magnetometers are installed with the orientation of the sensors in the HDZ system (with the horizontal axis X toward the magnetic north at the time of installation). This greatly simplifies the setting, but creates methodical difficulties during the processing of data, for example, when the variations of the horizontal components recorded by different instruments are compared;

2) all magnetometers, with the exception of POS-4, have an automatic synchronization of the internal timer with the UTC, using built-in GPS receivers. This ensures long-term stability of the timer, however, in some cases, when GPS synchronization failures (for example, in the MAGDAS and the recorder Magdalog), cause problems with timestamps of the data; 
3) the used vector magnetometers for continuous recording are based on various physical principles of measurements: FGE, MAGDAS and FRG-601 are fluxgate devices, STELAB is induction magnetometer and dIdD GSM-9FD and POS-4 use the scalar sensors in ring system. This makes it possible to significantly improve the efficiency of comparing the data obtained by them, including the identification of noise, the malfunctioning equipment or the detection of the effects like temperature ones. In addition, in some cases there are methodical advantages. For example, the baseline values of the $\mathrm{dIdD}$ magnetometer are estimated by direct comparison of the variations $\mathrm{dF}, \mathrm{dD}$ and $\mathrm{dI}$ with the absolute values of F, D, I obtained by absolute observations. Unlike dIdD the calculation of baseline values for other variometers requires the conversion of the absolute values of $\mathrm{F}, \mathrm{D}$, I to orientation system of variometer, which is the source of the errors;

4) magnetometers are installed in various places (on different pillars, in different pavilions), forming a gradiometric system with bases of various lengths and orientations. Magnetic measurements by such system are very effective for identification of the sources of noise in the observatory environment. In addition, the location of magnetometers in various pavilions allows us to have undisturbed magnetic data during the repair or adjustment of equipment;

5) standard processing is performed practically for all variation magnetometers and include the baseline calculation and estimation of the total field components. With this approach, there is a high interchangeability of data and the filling of gaps in records of one instrument is accomplished by a simple "substitution" of data obtained by another device;

6) some magnetometers uses the suspended system of sensors (FGE, dIdD) to compensate the slow inclinations of the pillar or sensors. Such systems increase the long-term stability of measurements, but they are sensitive to mechanical motion of the base: for example, after earthquakes the seismic waves moved near pillar produce the oscillations of suspended system with sensors, which causes the fictitious field variations up to hundreds of nT. Other magnetometers have rigid connection of the sensors with pillar and do not give similar effects (MAGDAS, FRG-601, POS-4). The MAGDAS magnetometer contains sensitive electronic levels that record the slopes of the device in the direction "north-south" and "east-west". In the POS-4 magnetometer the ordinary exact liquid levels are used, however they allow visually to fix only significant and slow slopes.

In the summer-autumn season at the station Karymshina, located near $15 \mathrm{~km}$ to the south-west of the observatory, measurements are performed using a magnetometer dIdD GSM-19FD. In other seasons the measurements at Karymshina are impossible due to a significant amount of precipitation (snow level at the end of spring may reach $6 \mathrm{~m}$ and more). Therefore, the risk of destruction of the pavilion increases and maintenance of the magnetometer is significantly complicated. The pavilion is a log house made of boards $50 \mathrm{~mm}$ thick, $2 \times 1 \mathrm{~m}$ in size, $1 \mathrm{~m}$ high, with a flat roof. The pillar is made of glass blocks, the total height is $0.7 \mathrm{~m}$, the height of the above-ground part is about $0.1 \mathrm{~m}$, the cross section is $0.4 \times 0.4 \mathrm{~m}$. $220 \mathrm{~V}$ power supply is supplied to the pavilion from the station's service room, the control and data collection is performed using RS232 protocol, the communication line length is about $20 \mathrm{~m}$ The measurements are performed in the standard mode, the data is available through the institute's local network.

In addition to the equipment for measuring the magnetic field, there are many devices at the Observatory Paratunka that are implicitly included in the magnetic monitoring system. First of all, these are temperature sensors, since many magnetometers are sensitive to changes of the temperature. The basis of the temperature control network is the digital sensors DS18B20, using parasitic power and communication with the recording computer on a single-wire line. The sensitivity of these sensors is $0.01{ }^{\circ} \mathrm{C}$, the accuracy in the range of seasonal and diurnal temperature variations is $0.5^{\circ} \mathrm{C}$. These sensors are joint very easy to network. Currently, about 15 sensors are located in magnetic pavilions at different altitude levels (for more details, see section 1) and outdoors at altitudes from 0.5 to $30 \mathrm{~m}$. In addition to the DS18B20 sensor network, temperature sensors built-in in magnetometers (MAG- 
DAS, FGE) and electric field meter CS110 and analog sensors based on thermoresistors are used. Meteorological parameters are monitored using Davis Vantage Pro II and WS2000 digital weather stations with remote sensors located at 10 and $20 \mathrm{~m}$ altitude and using the meteorological sensors of the CS110.

Observatory Paratunka was created as KMIS, that is, as a system for various geophysical measurements. At present, the initial structure of the observational system has changed significantly, but the principle of complexity remains the same: continuous observations of the ionosphere (vertical sounding by a digital ionosonde Parus), atmospheric electricity (electric field meters Pole-2 and CS110 for measurements of the vertical gradient of the potential Ez and the system Electrical conductivity2 for measurements of the electrical conductivity of the surface air layer) are performed. Also the measurements by the vertical seismic sensor and the microbarograph are made.

\section{Software and databases}

A large set of magnetometers and other measuring systems at the observatory requires developed software, which allows efficient processing and analysis of the recorded data. Such software on the Observatory Paratunka has been developed and continues to be modernized in accordance with changing tasks (see, for example, [13], [14]). The basic principles of the software are described in [15] and reflect the following features of use:

1) the software has a modular structure, which allows it to be easily adapted to a specific situation, for example, when input and output formats or equipment structure are changed, or when software is installed at other IKIR FEB RAS observatories;

2) the software is designed to be used by data processing by a magnetologist directly at the observatory, so it uses the maximal visualization of data during various steps of processing and provides the functions of interactive work with data;

3) the software reflects the basic requirements for the magnetic data processing at the INTERMAGNET observatories.

The structure of the software provides the following main functions:

- reading of raw data from files obtained during measurements by various magnetometers, the possibility of analyzing them, including the identification of noise and their correction;

- processing of the results of absolute magnetic observations and calculation of the baseline values of the variation magnetometers;

- daily processing of data, the calculation of total field components and minute values in accordance with INTERMAGNET standards, including minute values with the Quasi-definitive and Definitive status.

The most important function of the software used is the comparison of data obtained by various magnetometers. The comparison is performed at various stages of the processing, including the analysis of the raw data and the preparation of the resulting files. The functional diagram of the software for processing the data of the magnetometers FGE and GSM-90 is shown in Fig. 6. The software is developed as a package of scripts and functions for the Matlab system (http://www.mathworks.com/) and completely compatible with the Octave system (GNU GENERAL PUBLIC LICENSE, http://www.gnu.org/software/Octave/). The data is processed in the Matlab command window, in interactive mode. The choice of Matlab and Octave packages as a working environment for processing is due to their high efficiency for working with data series, the advanced graphical system and the support for calculations in command interpretation mode, when scripts and functions are represented as text files and loaded into memory after calling. The text format of scripts and functions provides the magnetologist the opportunity to easily modify them, if necessary, taking into account the real conditions arisen during processing. 


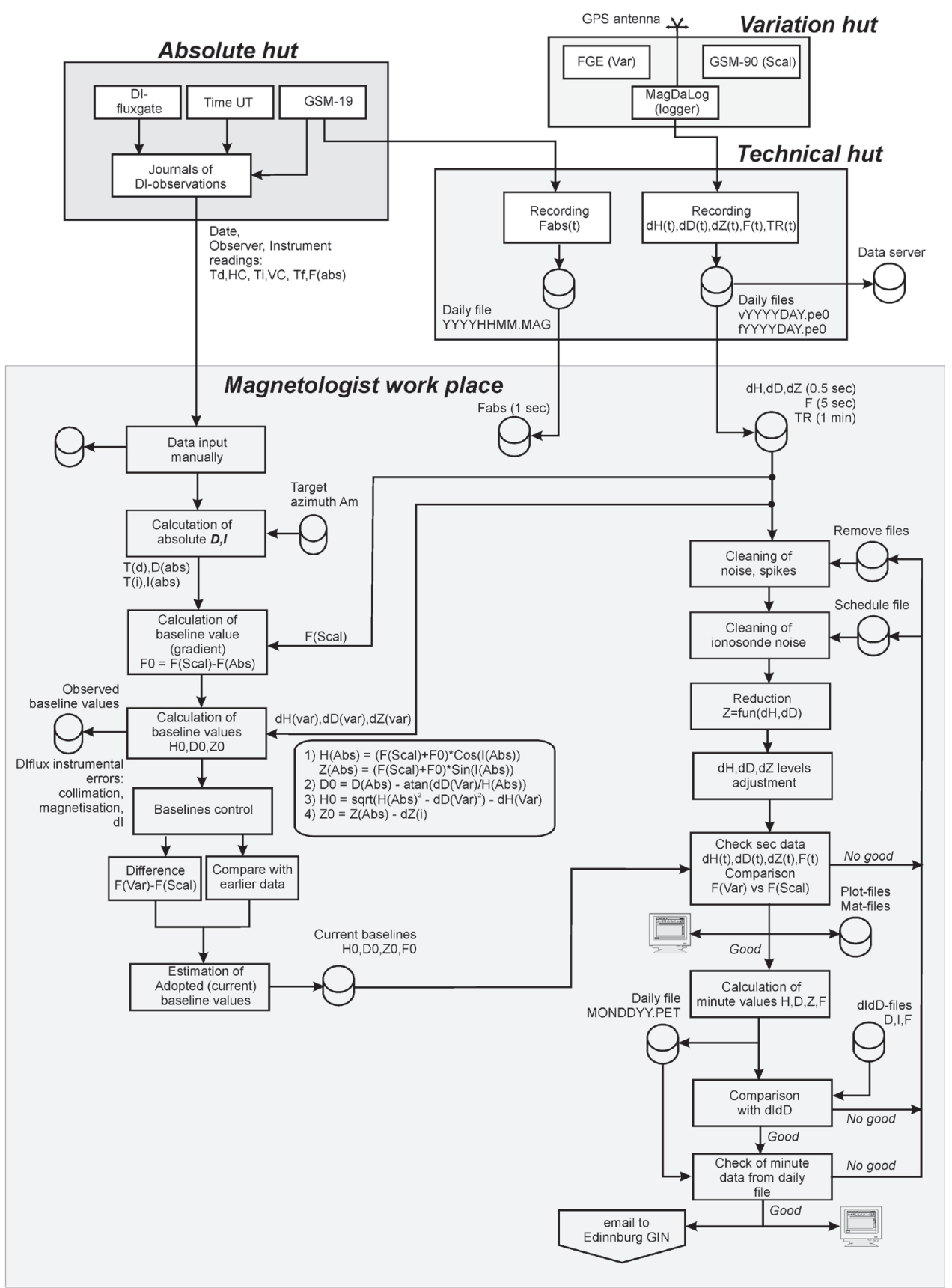

Figure 6. Diagram of full processing of the absolute observations (magnetometers LEMI-203 and GSM-19 or POS-1) and variation measurements (magnetometers FGE and GSM-90). The minute values in accordance with INTERMAGNET Standards with Reported and Adjusted status are the results of processing. 
The results of current measurements on the Observatory Paratunka are saved in databases (DB) at institute's data server and also locally on the some workstations of the observatory. DBs on the server collect new data automatically: every day after 24:00UT the archiving program (scripts in Shell envelope) copies new data from the recording computers of magnetometers and other measuring systems and performs service procedures, for example, logging and informing the server administrator. Local databases at the workstation are filled up manually, if it need to have the results of measurements in real time.

In addition to the database with the results of current measurements, the historical data are available at the Observatory Paratunka and are presented in international databases:

1) the hourly values of the H, D, Z, F of the total field vector (IAGA standard) were obtained by the Bobrov's quartz sensors with analog recording on photographic paper during 1969-2004 and are presented in the World Data Centres (http://www.wdc.bgs.ac.uk/catalog/master.html) before 1997;

2) the minute values $\mathrm{X}, \mathrm{Y}, \mathrm{Z}, \mathrm{F}$ of total field vector (INTERMAGNET standard) are obtained by digital vector and scalar magnetometers during 2007-2016 (http://intermagnet.org/data-donnee/dataeng.php);

3) the digital images of analogue magnetograms for 1967-2006 are obtained under support of grant "The creation of the database of images of old analogue magnetograms of Geophysical Observatory "Paratunka", Kamchatka, Russia, 1967-2006", VarSITI project [16]. The database is accessible from WDC (http://www.wdcb.ru/stp/magnetogr_list.en.html).

\section{Some applications of magnetic monitoring results}

Complete set of the equipment, advanced software, extensive archives and databases show that the Observatory Paratunka is a magnetic observatory that provides measurement of field variations at times from decades to seconds in accordance with IAGA and INTERMAGNET standards and provides an experimental basis for solving a wide range of fundamental and applied problems.

Near 50-year series of hourly data on the total field vector makes it possible to study slow variations of the magnetic field (secular variations), such as pole drift or jerks. Figure 6 shows the annual values of $\mathrm{H}, \mathrm{D}, \mathrm{Z}$ obtained at the Observatory Paratunka (data not presented in the WDC and required the verification, is not shown). Magnetic field changes calculated by the international model IGRF12 (www.ngdc.noaa.gov/IAGA/vmod/igrf.html) is also presented at Fig. 7. The inset shows a map (polar projection) with Russian magnetic observatories, which obtain the annual mean data during recent decades, and the position of the north magnetic pole during 20 years. Figure 7 shows that the Observatory Paratunka (PET) is the most eastern Russian observatory, on which regular observations of the total field vector are performed and provide a global representation for magnetic research. It is also clear that the IGRF12 model is good presented the slow field changes in Kamchatka, but there are significant constant differences, possibly related to an inadequate model description of the field in the region. These features are important for the fundamental basis of modeling the main Earth's magnetic field and its secular variations. In addition, the questions of correct modeling of the regional field are important, including the field of crust sources which necessary for inclined drilling [17].

Minute and second magnetic data obtained at the observatory in accordance with the standards of INTERMAGNET, are basic for many scientific studies and in applied problems. This is, for example, the study of processes in the magnetosphere and the ionosphere, including the processes with regional scales or related to Space Weather [18], [19], the study of the Earth's interior [20], the correlation of geophysical processes in the near-Earth atmosphere [21] and many others. An important applied aspect of magnetic measurements is the possible connection between variations of geophysical fields, for example, between magnetic field and seismicity of Kamchatka [22], [23]. High-frequency magnetic 

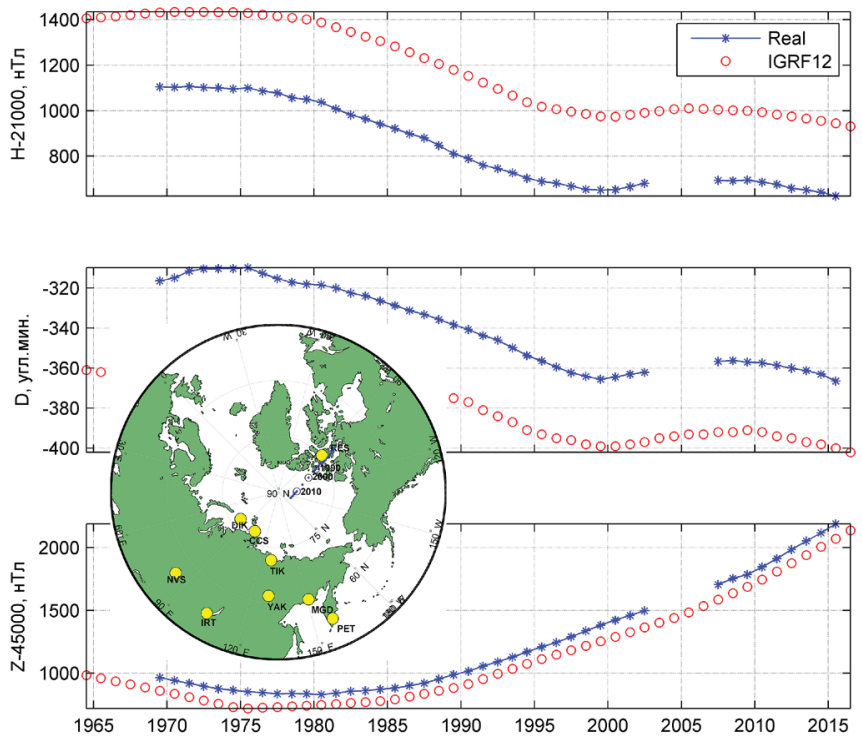

Figure 7. Slow changes of magnetic field at the Observatory Paratunka (PET) from real magnetic observations and by global model IGRF12 (annual mean values). The inset shows magnetic observatories at eastern region of Russia and the location of North magnetic pole.

measurements by induction magnetometer at the observatory provide information on fast processes in the magnetosphere and ionosphere [24], [25], [26].

Observatory Paratunka with a large set of various magnetometers and developed infrastructure makes it an important element in applied works:

- during magnetic surveys of various levels the Observatory can be the center of the reference data about field variations in the region. In addition, before and after field season the calibration and verification of field equipment can be carried out at Observatory;

- the Observatory can be the base point for magnetic measurements at the Repeat Stations (RS) network (the observation program on RSs was stopped in the 90's, but its relevance is now increasing);

- calibration and reconciliation of magnetometers and compasses used by various organizations for stationary and field observations can be performed on the Observatory (comparison of DIflux and scalar magnetometers of the Observatory Magadan was performed at the Observatory Paratunka in October 2012, similar comparison of Geophysical Center of RAS was performed in December 2014);

- Observatory Paratunka has a full set of field instruments for magnetic measuring the total field vector, including the absolute magnetometers Mag-01 and GSM-19W and a variation magnetometer dIdD GSM-19FD. In addition, a new vector magnetometer POS-4 is being tested on the Observatory and can be used in the field surveys. 


\section{Conclusions}

The Geophysical observatory Paratunka was organized fifty years ago. Today this is modern observatory, where the Earth's magnetic field is observed in accordance with high international requirements and standards. The modern digital equipment, the advanced software and the presence of a developed infrastructure allow to obtain the high quality results necessary for solving of fundamental scientific and applied tasks. The Observatory Paratunka is certified as a magnetic observatory of the INTERMAGNET and is the coordinating center for magnetic measurements at other IKIR FEB RAS observatories (Magadan, Khabarovsk and Cape Schmidt). The observatory carries out measurements in cooperation with scientific organizations of Japan, Germany and India.

Further development of the Observatory supposes its participation in regional magnetic survey, including the Repeat Stations program, in studies of the regional features of magnetosphericionospheric processes and also in studies of the seismic activity of Kamchatka.

The author is grateful to the staff of the Observatory Paratunka, who for 50 years have provided and continue to provide high-quality measurements of the magnetic field in Kamchatka. This work was partial supported by grants of RFBR No.16-55-45007 and RSF No.14-11-00194.

\section{References}

[1] DS18B20 Programmable Resolution 1-Wire Digital Thermometer, https://datasheets.maximintegrated.com/en/ds/DS18B20.pdf, 20 (2015)

[2] I.Y. Babakhanov, M.Y. Basalaev, Z.F. Dumbrava, I.N. Poddelsky, S.Y. Khomutov, VI Int. Conf. Solar-Terrestrial Relations and Physics of Earthquakes Precursors, 234-238 (2013), in Russian

[3] S.Y. Khomutov, I.Y. Babakhanov, M.L. Basalaev, Z.F. Dumbrava, I.N. Poddelsky, Materials of the Partnership conference "Geophysical observatories, multifunctional GIS and data mining", Geoinf. Res. Papers, BS1004, doi:10.2205/2013BS012_Kaluga, http://ebooks.wdcb.ru/doi/kaluga_conf.html (2013)

[4] S. Khomutov, V. Sapunov, A.Denisov, D. Savelyev, I. Babakhanov, E3S Web Conf., VII International Conference "Solar-Terrestrial Relations and Physics of Earthquakes Precursors", 11, 7 (2016)

[5] INTERMAGNET technical reference manual. Version 4.6, Edited by Benoit St-Louis, 92 (2012)

[6] J.L. Rasson, A.S. Potapov, V.E. Korepanov, S.Y. Khomutov, V.M. Krasnov, J. Bitterly, Earth Planets Space, 58, 717-722 (2006)

[7] MAGDAS-A Installation Manual, SERC, Kyushu Univ., Editor George N. Maeda, 35 (2005)

[8] dIdD v.7.0 Insrtuction Manual. GEM Systems, Canada, 50 pp.(2010)

[9] POS-1 Processor Overhauser Sensor - Magnetometer. User Manual, Ural State Technical University, 21 (2004)

[10] Observatory / Volcanology Magnetometer (GSM-90 v7.0), GEM Systems, Inc. (2008)

[11] GSM-19 v7.0 Instruction Manual. GEM Systems, Canada, 149 pp. (2008)

[12] Operation Manual for Mag-01H Fluxgate Declinometer/Inclinometer with non-magnetic WILD T1 Theodolite (OM2020 Issue 4), Bartington Instruments Ltd., 27 (2012)

[13] S.Y. Khomutov, I.Y. Babakhanov, M.L. Basalaev, Z.F. Dumbrava, I.N. Poddelsky, Modern Information Technologies in Earth Sciences, $42-43$ (2014), in Russian

[14] S.Y. Khomutov, Software for processing of results of magnetic measurements and preparing of data in accordance with INTERMAGNET Standards. Certificate of Rospatent No2016610829. (2016), in Russian 
[15] S.Y. Khomutov, Ind. Geophys. Union (Special Volume), 2, 54-61 (2016)

[16] S.Y. Khomutov, VarSITI Newletter, 3, 7-8 (2014)

[17] I.M. Demina, A.A. Petrova, Bulletin of KRAESC. Earth Sci., 1(15), 206-215 (2010), in Russian

[18] D.G. Baishev, A.V. Moiseyev, R.N. Boroyev, S.E. Kobyakova, A.E. Stepanov, O.V. Mandrikova, I.S. Solovev, S.Yu. Khomutov, Yu.A. Polozov, A. Yoshikawa, K. Yumoto, Sun and Geosphere, 10, 133-140 (2015)

[19] O.V. Mandrikova, T.L. Zalyaev, I.S. Soloviev, S.Y. Khomutov, Bulletin of KRAESC. Phys.Math.Sci., 3(10), 40-46 (2016), in Russian

[20] Y.F. Moroz, T.A. Moroz, S.E. Smirnov, Izvestiya, Physics of the Solid Earth, 8, 49-61 (2011), in Russian

[21] S.E. Smirnov, G.A. Mikhaylova, O.V. Kapustina, Geomagnetism and aeronomy, 53, 532-545 (2013)

[22] A.V. Buzevich, S.E. Smirnov, The problems of geodynamics and earthquake prediction, 285 (2001), in Russian

[23] The method of detection of earthquake precursors, http://www.emsd.ru/265-methods-eq (2017), in Russian

[24] K. Shiokawa, R. Nomura, K. Sakaguchi, Y. Otsuka, Y. Hamaguchi, M. Satoh, Y. Katoh, Y. Yamamoto, B.M. Shevtsov, S. Smirnov, I. Poddelsky, M. Connors, Earth Planets Space, 62, 517$524(2010)$

[25] R.A. Rakhmatulin, A.Y. Pashinin, Y.V. Lipko, S.Y. Khomutov, I.Y. Babakhanov, Solar-Terr. Phys., 24, 64-69 (2013)

[26] V.A. Parkhomov, N.L. Borodkova, A.V. Yakhnin, B. Tsegmed, V.E. Chilikin, S.Y. Khomutov, A.V. Pashinin, B.V. Dovbnya, Physics of auroral phenomena. The 40th annual seminar, 13-17 March, 2017. Abstract Book, 47 (2017) 